\section{Efecto antimicrobiano del extracto hidroalcohólico de allium sativum sobre cepas estándares de la cavidad bucal}

\author{
Antimicrobial effect of hydroalcoholic extract of Allium sativum strains on \\ standards of the oral cavity
}

\section{Resumen}

El objetivo del presente estudio fue determinar el efecto antimicrobiano y antifúngico del extracto de Allium sativum frente a las cepas ATCC de S. mutans, Capnocytophaga sputigena, Lactobacillus casei y C. albicans a diversas concentraciones. El extracto se obtuvo por el proceso de maceración y para la prueba experimental, se utilizó el método de difusión mediante discos: ciprofloxacino y el fluconazol como control positivo de las bacterias y hongo, respectivamente y el alcohol de $70^{\circ}$ como control negativo. Al realizar las pruebas de sensibilidad con el extracto a las concentraciones de $12 \mathrm{mg} / \mathrm{mL}, 18 \mathrm{mg} / \mathrm{mL}$ $30 \mathrm{mg} / \mathrm{mL}, 60 \mathrm{mg} / \mathrm{mL}, 90 \mathrm{mg} / \mathrm{mL}, 120 \mathrm{mg} / \mathrm{mL}$, se obtuvo los siguientes resultados: La concentración antimicrobiana frente al Capnocytophaga sputigena, Streptococcus mutans y Candida albicans, fue de $120 \mathrm{mg} / \mathrm{mL}$, teniendo como referencia como estándar al ciprofloxacino a una concentración de $4 \mathrm{mg} / \mathrm{ml}$ y al fluconazol a una concentración de $2 \mathrm{mg} / \mathrm{ml}$. Se concluye que el extracto hidroalcohólico de Allium sativum presentó efecto antimicrobiano frente a la cepa ATCC de S. mutans, Capnocytophaga sputigena, y C. albicans a excepción de Lactobacillus casei que presentó resistencia.

Palabra clave: Antibioticos, extractos celulares, boca, bacterias.

\begin{abstract}
The aim of this study was to determine the antimicrobial and antifungal effect of Allium sativum extract against ATCC strains of S. mutans, Capnocytophaga sputigena, Lactobacillus casei and C. albicans at various concentrations. The extract was obtained by the mashing process and the experimental test, was used by disk diffusion method: ciprofloxacin and fluconazole as positive control of bacteria and fungi, respectively and alcohol 70 as a negative control. When performing susceptibility testing with the extract at concentrations of $12 \mathrm{mg} / \mathrm{ml}, 18 \mathrm{mg} / \mathrm{ml} 30 \mathrm{mg} / \mathrm{ml}, 60 \mathrm{mg} / \mathrm{mL}, 90 \mathrm{mg} / \mathrm{mL}, 120 \mathrm{mg} / \mathrm{mL}$, we obtained the following results: The antimicrobial concentration versus sputigena Capnocytophaga, Streptococcus mutans and Candida albicans, was $120 \mathrm{mg} / \mathrm{mL}$, taking as reference standard to ciprofloxacin at a concentration of $4 \mathrm{mg} / \mathrm{ml}$ and fluconazole at a concentration of $2 \mathrm{mg} / \mathrm{ml}$. Concluded that the hydroalcoholic extract of Allium sativum presented antimicrobial effect against $S$. strain ATCC mutans, Capnocytophaga sputigena, and C. albicans except that showed resistance Lactobacillus casei.
\end{abstract}

Keyword: Antibiotics, bacteria, cell extracts, mouth.
Artículo Original

\section{Evelyn Munayco Pantoja ${ }^{1}$, Hilda Moromi Nakata²}

1 Cirujano Dentista, estudiante de posgrado, UNMSM.

2 Docente - investigador Instituto de Investigación Estomatológica, UNMSM.

Correspondencia:

Evelyn Munayco Pantoja

Dirección: Jr. Huacarunco 153 - Maranga, San Miguel

Correo Electrónico: mielina30@hotmail.com

Fecha de recepción: 16-07-2013

Fecha de aceptación: 04-09-2013

\section{Introducción}

En vista que el mayor porcentaje de nuestra población presenta bajos recursos económicos, la medicina tradicional, entre ellos la medicina herbal, trata de buscar alternativas de solución a enfermedades bucales, con hierbas medicinales, como productos económicos y prácticos. El resurgimiento en el uso de alternativas naturales a base de hierbas ha traído el uso de plantas medicinales a la vanguardia de los estudios farmacológicos, y muchos medicamentos nuevos que se descubren.

Dentro de estas hierbas medicinales, encontramos estudios con llantén,
Plantago major, que presenta actividad antiinflamatoria en gingivitis inducida, ${ }^{2}$ el gel de Aloe vera, Aloe vera linnaeus, que presenta acción antiinflamatoria a nivel gingival, ${ }^{3}$ la muña, Minthostachys griseb, que presenta actividad antibacteriana frente a seis microorganismos de la microflora oral, ${ }^{4}$ entre otros.

El presente estudio buscó la aplicación del extracto hidroalcohólico del Allium sativum frente a bacterias de la cavidad oral, para determinar su acción antimicrobiana partiendo de diseńos previos en la cual se llegó a la conclusión de que el extracto hidroalcohólico presenta mejor propiedad antimicrobiana que el extracto acuoso u orgánico.
Mercado S en el 2006, determinó el efecto antibacteriano del ajo en bacterias patógenas de la microflora salival. Los resultados obtenidos demuestran que la concentración mínima inhibitoria del ajo aplicado en la microflora bacteriana salival es de $0,8 \mathrm{gr} / \mathrm{ml}$ y la concentración mínima bactericida es de 2, $0 \mathrm{gr} / \mathrm{ml} .^{5}$

Villanueva G en el 2007, determinó la actividad antibacteriana del extracto de Allium sativum sobre el Streptococcus mutans, en condiciones in vitro. La Concentración Mínima Inhibitoria (CMI) es de 2, $00 \mathrm{mg} / \mathrm{ml}^{6}$ 
El presente estudio trata de demostrar el efecto antimicrobiano y antifúngico del extracto hidroalcohólico del Allium sativum frente a cepas estándares de la cavidad oral, como una alternativa, que beneficie a la población peruana en especial de bajos recursos económicos, en la prevención para la preservación de la salud bucal.

\section{Material y métodos}

El presente estudio es de tipo experimental, prospectivo e in vitro. Se trabajó con grupos controles, un control positivo representado por ciprofloxacino para las bacterias y un antimicótico representado por el Fluconazol, para Candida albicans (Hongo) y un control negativo representado por alcohol al $50 \%$. Se utilizó cepas de Streptococcus mutans 25175, Lactobacillus casei 4356, Capnocytophaga sputigena 33612 y Candida albicans 10231 procedentes del American Culture Collection (ATCC) y con el extracto hidroalcohólico del Allium sativum a diferentes concentraciones: $1,2 \mathrm{mg} / \mathrm{mL}, 18 \mathrm{mg} / \mathrm{mL} 30 \mathrm{mg} /$ $\mathrm{mL}, \quad 60 \mathrm{mg} / \mathrm{mL}, \quad 90 \mathrm{mg} / \mathrm{mL}, 120 \mathrm{mg} /$ $\mathrm{mL}$.

\section{Obtención y purificación del extracto}

Para la obtención del extracto hidroalcohólico, se utilizó la instalaciones del Centro de Control Analítico de la Facultad de Farmacia y Bioquímica de la UNMSM. El extracto se obtuvo por el proceso de maceración; para el cual se emplearon 500mg de bulbos de Allium sativum, que fueron colocados en una solución hidroalcohólica al $70 \%$, estos fueron sometidos al proceso de maceración por un periodo de 6 días en un recipiente de vidrio ámbar sin cámara de oxigeno. La purificación del extracto con la finalidad de eliminar el sobrenadante se realizó con un equipo convencional de filtrado empleando papel whatman $\mathrm{No}^{2} 2$, en un tiempo aproximado de 20 minutos. La solución del extracto hidroalcohólico de Allium sativum obtenida, se filtró a través de un filtro millipore de diámetro de $0.44 \mu \mathrm{m}-0.22 \mu \mathrm{m}$, en un tiempo aproximado de 1 hora. Se determinó la concentración del extracto de Allium sativum por el método de pérdida por secado (donde se tomó una alícuota del extracto y es sometida a sequedad bajo condiciones controladas). Se realizó la marcha fotoquímica para saber los componentes del extracto de Allium sativum, los cuales fueron corroboradas por cromatografía de capa fina frente a estándares. Después de obtenido el extracto hidroalcohólico, se procedió a la preparación de las cepas ATCC y su posterior reactivación, como se detalla a continuación

\section{Preparación del material biológico}

Reactivación de las cepas bacterianas y fúngicas por el método de recuperación en placa donde se trabajó con cepas estándares ATCC (American Type Culture Collection) según las condiciones descritas en la tabla 1 .

Tabla 1. Cultivos de Cepas bacterianas ATCC

\begin{tabular}{ccccc}
\hline MICROORGANISMO & MEDIO DE CULTIVO & TIEMPO & TIEMPO & INCUBACION \\
\hline $\begin{array}{c}\text { Streptococcus mutans } \\
\text { ATCC 25175 }\end{array}$ & Agar Mueller-Hinton & $37^{\circ} \mathrm{C}$ & 24 horas & $\begin{array}{c}\text { Con reactivo } \\
\text { para co2 }\end{array}$ \\
$\begin{array}{c}\text { Candida albicans } \\
\text { ATCC 10231 }\end{array}$ & Agar Sabouraud & $37^{\circ} \mathrm{C}$ & $48-72$ horas & Aerobiosis \\
$\begin{array}{c}\text { Lactobacillus casei } \\
\text { ATCC 393 }\end{array}$ & Agar Rogosa & $37^{\circ} \mathrm{C}$ & 24 horas & $\begin{array}{c}\text { Con reactivo } \\
\text { para co2 }\end{array}$ \\
$\begin{array}{c}\text { Capnocytophaga sputi- } \\
\text { gena ATCC } 33612\end{array}$ & Agar Schaedler & $37^{\circ} \mathrm{C}$ & $48-72$ horas & $\begin{array}{c}\text { Con reactivo } \\
\text { para co2 }\end{array}$ \\
\hline
\end{tabular}

Prueba de sensibilidad antimicrobiana ${ }^{7}$

El procedimiento es el mismo en todos los microorganismos, por eso se tomó como referencia al Streptococcus mutans ATCC 25175 . En $2 \mathrm{ml}$ de suero fisiológico contenido en un tubo de ensayo se procedió a preparar el inóculo para el desarrollo de la parte experimental. A partir del cultivo de la placa de agar
Mueller-Hinton, con un asa de Kolle se retiró suficientes colonias que fueron colocadas en el tubo de ensayo, hasta que la turbidez fuera igual que la escala 1 de Mc Farland $\left(3 \times 10^{8} \mathrm{UFC} / \mathrm{ml}\right)$.

Se procedió a medir en una probeta $50 \mathrm{ml}$ del Agar Mueller-Hinton mantenido a una temperatura de $45{ }^{\circ} \mathrm{C}$, se agregó el contenido del inoculo del tubo de ensayo, para después verterlo sobre la placa petri de $150 \mathrm{mmx} 15 \mathrm{~mm}$ estéril hasta la solidificación. En condiciones estériles se procedió con un sacabocados de $11 \mathrm{~mm}$ de diámetro a formar los 8 pozos los cuales tuvieron una altura de $5 \mathrm{~mm}$, luego se colocó en cada pozo $60 \mu \mathrm{L}$ de cada concentración del extracto al $12 \mathrm{mg} / \mathrm{mL}, 18 \mathrm{mg} /$ $\mathrm{mL}, 30 \mathrm{mg} / \mathrm{mL}, 60 \mathrm{mg} / \mathrm{mL}, 90 \mathrm{mg} / \mathrm{mL}$, $120 \mathrm{mg} / \mathrm{mL}$ y los controles negativos y positivos. Se dejó reposar aproximadamente 10 minutos. Este ensayo se hizo por triplicado. Se incubó las 3 placas a $37{ }^{\circ} \mathrm{C}$ por 24 - 48 horas.

\section{Resultados}

Extracto de Allium sativum; se obtuvo $108 \mathrm{~g}$ de extracto seco por cada $500 \mathrm{mg}$ de bulbo de ajos macerada en $1500 \mathrm{~mL}$ solvente (etanol al $70 \%$ ), mediante la técnica de maceración.

\section{Acción antimicrobiana}

Se estudió el diámetro de los halos de inhibición formado por el extracto de Allium sativum a distintas concentraciones, teniendo como referente dos controles positivos ciprofloxacino, fluconazol y un control negativo.

\section{Acción antimicrobiana frente a Candi-} da albicans ATCC 10231

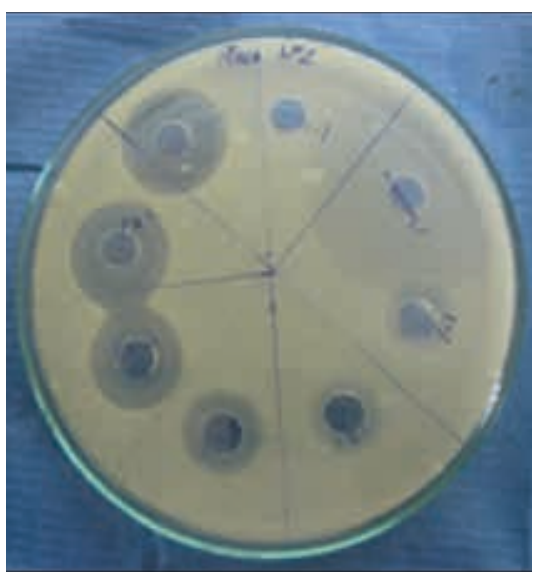

Fig 1. Formación de halos de inhibición de Candida albicans ATCC 10231 en Agar Sabouraud

Se realizaron 3 ensayos válidos para cada concentración donde se obtuvieron los resultados observados en la Fig. 1 , donde se midieron los halos de inhibición, los cuales fueron registrados en la Tabla 2. Los halos de inhibición tuvieron una media de $16 \mathrm{~mm}, 19 \mathrm{~mm}$, $21 \mathrm{~mm}, 24 \mathrm{~mm}, 28 \mathrm{~mm}$ y $31 \mathrm{~mm}$ trabajada a las distintas concentraciones (Tabla 2) y el fluconazol tuvo una media de $32 \mathrm{~mm}+/-2$. 
Tabla 2: Efecto del extracto Allium sativum vs. Fluconazol en cepas Candida albicans

\begin{tabular}{ccccccccc}
\hline & \multicolumn{4}{c}{ Concentración del extracto } & CONTROL \\
\cline { 2 - 7 } No Placa & 12 & 18 & 30 & 60 & 90 & 120 & $\begin{array}{c}\text { POSITIVO } \\
\text { (FLUCONA- } \\
\text { CONTROL }\end{array}$ & $\begin{array}{c}\text { NEGATIVO } \\
\text { ZOL). }\end{array}$ \\
\hline PLACA N01 & 13 & 19 & 22 & 23 & 30 & 32 & 34 & 0 \\
PLACA N02 & 18 & 19 & 21 & 25 & 27 & 30 & 30 & 0 \\
PLACA N 3 & 16 & 18 & 21 & 25 & 27 & 30 & 32 & 0 \\
Promedio & $16 \mathrm{~mm}$ & $19 \mathrm{~mm}$ & $21 \mathrm{~mm}$ & $24 \mathrm{~mm}$ & $28 \mathrm{~mm}$ & $31 \mathrm{~mm}$ & $32 \mathrm{~mm}$ & $0 \mathrm{~mm}$ \\
\hline
\end{tabular}

Acción antimicrobiana frente Streptococcus mutans ATCC 25175

Se realizaron 3 ensayos válidos para cada concentración donde se obtuvieron los resultados observados en la Fig. 2, donde se midieron los halos de inhibición, los cuales fueron registrados en la Tabla 3.

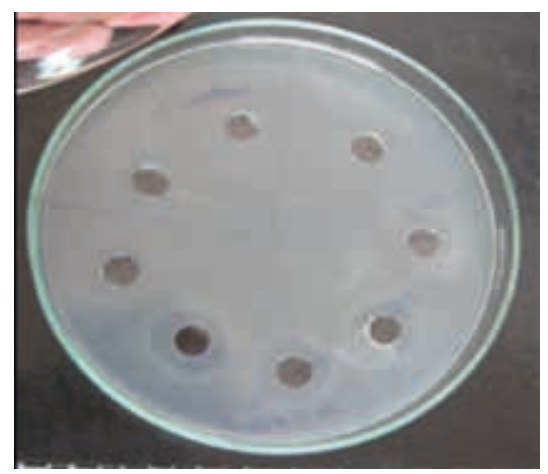

Fig 2. Formación de halos de inhibición en Streptococcus mutans ATCC 25175 en Agar Mueller-Hinton

Los halos de inhibición tuvieron una media de $17 \mathrm{~mm}, 19 \mathrm{~mm}, 21 \mathrm{~mm}$, $23 \mathrm{~mm}, 27 \mathrm{~mm}$ y $32 \mathrm{~mm}$ trabajada a

las distintas concentraciones (Tabla 3) y el ciprofloxacino tuvo una media de $32 \mathrm{~mm}+/-1$

Se realizaron 3 ensayos válidos para cada concentración donde se obtuvieron los siguientes resultados observados en la Fig. 3, donde se midieron los halos de inhibición, los cuales fueron registrados en la Tabla 4.

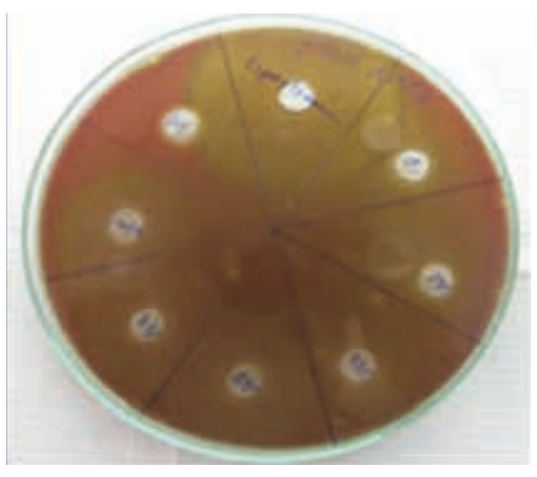

Fig. 3: Formación de halos de inhibición en Capnocytophaga sputigena ATCC 33612 en Agar Schaedler

Tabla 3: Efecto del extracto Allium sativum vs. Ciprofloxacino en cepas Streptococcus mutans

\begin{tabular}{|c|c|c|c|c|c|c|c|c|}
\hline \multirow[b]{2}{*}{ No Placa } & \multicolumn{6}{|c|}{ Concentración del extracto } & \multirow[b]{2}{*}{$\begin{array}{l}\text { C POSITIVO } \\
\text { Ciprofloxacino }\end{array}$} & \multirow[b]{2}{*}{$\begin{array}{l}\text { CONTROL } \\
\text { NEGATIVO }\end{array}$} \\
\hline & $\begin{array}{c}12 \\
\mathrm{mg} / \mathrm{ml}\end{array}$ & $\begin{array}{c}18 \\
\mathrm{mg} / \mathrm{ml}\end{array}$ & $\begin{array}{c}30 \\
\mathrm{mg} / \mathrm{ml}\end{array}$ & $\begin{array}{c}60 \\
\mathrm{mg} / \mathrm{ml}\end{array}$ & $\begin{array}{c}90 \\
\mathrm{mg} / \mathrm{ml}\end{array}$ & $\begin{array}{c}120 \\
\mathrm{mg} / \mathrm{ml}\end{array}$ & & \\
\hline PLACA No 1 & 17 & 19 & 23 & 24 & 28 & 30 & 32 & 0 \\
\hline PLACA N² & 16 & 18 & 20 & 22 & 26 & 35 & 33 & 0 \\
\hline PLACA N $^{0} 3$ & 17 & 20 & 20 & 22 & 28 & 30 & 30 & 0 \\
\hline Promedio & $17 \mathrm{~mm}$ & $19 \mathrm{~mm}$ & $21 \mathrm{~mm}$ & $23 \mathrm{~mm}$ & $27 \mathrm{~mm}$ & $32 \mathrm{~mm}$ & $32 \mathrm{~mm}$ & $0 \mathrm{~mm}$ \\
\hline
\end{tabular}

Acción antimicrobiana frente Capnocytophaga sputigena ATCC 33612

Tabla 4: Efecto del extracto Allium sativum vs. Ciprofloxacino en cepas Capnocytophaga sputigena

\begin{tabular}{|c|c|c|c|c|c|c|c|c|}
\hline \multirow[b]{2}{*}{ No Placa } & \multicolumn{6}{|c|}{ Concentración del extracto } & \multirow{2}{*}{$\begin{array}{l}\text { C POSITIVO } \\
\text { (Ciprofloxa- } \\
\text { cino). }\end{array}$} & \multirow[b]{2}{*}{$\begin{array}{l}\text { C. NEGA- } \\
\text { TIVO }\end{array}$} \\
\hline & $\begin{array}{c}12 \\
\mathrm{mg} / \mathrm{ml}\end{array}$ & $\begin{array}{c}18 \\
\mathrm{mg} / \mathrm{ml}\end{array}$ & $\begin{array}{c}30 \\
\mathrm{mg} / \mathrm{ml}\end{array}$ & $\begin{array}{c}60 \\
\mathrm{mg} / \mathrm{ml}\end{array}$ & $\begin{array}{c}90 \\
\mathrm{mg} / \mathrm{ml}\end{array}$ & $\begin{array}{c}120 \\
\mathrm{mg} / \mathrm{ml}\end{array}$ & & \\
\hline PLACA N ${ }^{0} 1$ & 17 & 17 & 31 & 35 & 37 & 43 & 44 & 0 \\
\hline PLACA N² & 20 & 20 & 32 & 36 & 40 & 46 & 47 & 0 \\
\hline PLACA N ${ }^{\circ} 3$ & 20 & 22 & 32 & 35 & 40 & 42 & 43 & 0 \\
\hline Promedio & $19 \mathrm{~mm}$ & $20 \mathrm{~mm}$ & $32 \mathrm{~mm}$ & $35 \mathrm{~mm}$ & $39 \mathrm{~mm}$ & $44 \mathrm{~mm}$ & $45 \mathrm{~mm}$ & $0 \mathrm{~mm}$ \\
\hline
\end{tabular}

Acción antimicrobiana frente Lactobacillus casei ATCC 393
Los halos de inhibición tuvieron una media de $19 \mathrm{~mm}, 20 \mathrm{~mm}, 32 \mathrm{~mm}$, $35 \mathrm{~mm}, 39 \mathrm{~mm}$ y $44 \mathrm{~mm}$ trabajada a las distintas concentraciones (tabla 4) y el ciprofloxacino tuvo una media de $45 \mathrm{~mm}+/-2$

Se realizaron 3 ensayos válidos para cada concentración donde se obtuvieron los siguientes resultados observados en la Fig. 4, donde se midió el halo de inhibición del control positivo, el cual tuvo de promedio $42 \mathrm{~mm}$, además se observo que no hubo inhibición antibacteriana para el extracto de Allium sativum.

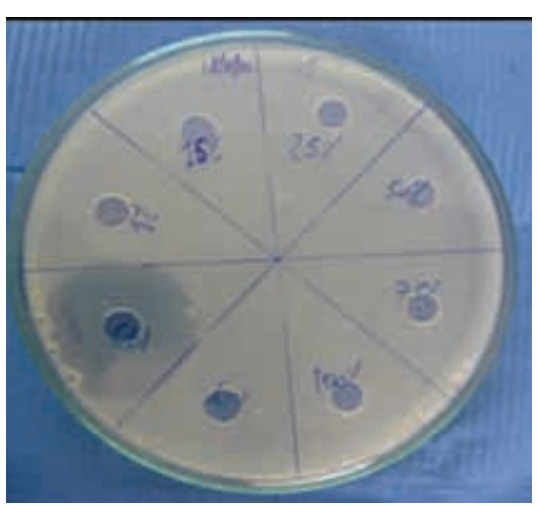

Fig. 4: Formación de halo de inhibición (control positivo) en Lactobacillus casei ATCC 393 en Agar Rogosa

Se procedió al análisis estadístico

Prueba de normalidad, demostrando los resultados tienen una distribución normal al $95 \%$ de nivel de confianza.

Prueba de igualdad de varianzas donde la varianza a distintas concentraciones son iguales con un $95 \%$ de nivel de confianza.

Prueba de Anova se demostró que a diferentes concentraciones estadísticamente los resultados no son iguales.

Re-Tes Anova entre las concentraciones de $90 \mathrm{mg} / \mathrm{mL}$ y $120 \mathrm{mg} / \mathrm{mL}$ comparadas con el estándar demostró que los resultados son estadísticamente iguales con un $95 \%$ de nivel de confianza.

\section{Discusión}

En esta investigación se propuso validar la actividad antimicrobiana y antifúngica del Allium sativum contra Streptococcus mutans, microorganismo cariogénico por excelencia, ${ }^{8}$ contra Lactobacillus case $i$, bacteria responsable del avance de la caries en la profundidad del esmalte y la dentina, ${ }^{8}$ contra Capnocytophaga sputigena, bacteria periodontopatoge$n \mathrm{n}^{8}$ y contra Candida albicans, hongo 
implicado en la candidiasis oral. ${ }^{8}$ Estos microorganismos también fueron estudiados por otros investigadores. ${ }^{6} \mathrm{y} 9$

García Rico 2007, evaluó la inhibición del extracto del Allium sativum, Allium fistulosum y Allium sobre cinco cepas bacterianas, utilizando el extracto acuoso, con una metodología muy similar al presente estudio, para la determinación de la actividad antimicrobiana obtuvo con el extracto acuoso de Allium sativum menor potencial antibacteriano a diferencia de los resultados obtenidos en esta investigación en que se utilizó el extracto hidroalcohólico, sobre 4 cepas. ${ }^{10}$

Naupari Valdivieso 2007, estudió el efecto antifúngico del extracto de Allium sativum frente a la Candida albicans, utilizando concentraciones de 5 , 10, 20, 40 y $80 \mathrm{mg} / \mathrm{mL}$ del extracto ${ }^{6}$ a diferencia de esta investigación donde las concentraciones del extracto fue de $12,18,30,60,90$ y $120 \mathrm{mg} / \mathrm{mL}$. En dicho estudio halló que en todas las concentraciones experimentadas, Candida albicans inhibía su crecimiento. En la presente investigación se obtuvo halos de inhibición en todas las concentraciones usadas, pero no todas ellas eran semejantes a la acción antifúngica del fluconazol. En ambos estudios se usó al Fluconazol como control positivo. Asimismo el extracto de Allium sativum dio un promedio de halo de inhibición de $28,3 \mathrm{~mm}$ en contraste con el estudio de Naupari ${ }^{6}$, que daba un promedio de $23,13 \mathrm{~mm}$ por cual la diferencia no es estadísticamente significativa. Naupari ${ }^{6}$ trabajo con el fluconazol a una concentración de $10 \mathrm{mg} / \mathrm{ml}$ y obtuvo un halo de inhibición de $31,6 \mathrm{~mm}$ de promedio; a diferencia de la presente investigación donde se empleó fluconazol a una concentración de $2 \mathrm{mg} / \mathrm{ml}$, produciendo un halo de inhibición de $32 \mathrm{~mm}$ de promedio. A pesar de utilizar diferentes concentraciones del fluconazol $(10 \mathrm{mg} / \mathrm{ml}$ y $2 \mathrm{mg} / \mathrm{ml})$, la diferencia en el promedio del halo de inhibición $(31,67 \mathrm{~mm}$ y $32 \mathrm{~mm})$ no es estadísticamente significativa.

\section{Conclusiones}

El extracto hidroalcohólico de Allium sativum presentó efecto antimicrobiano frente a la cepa ATCC de S. mutans, Capnocytophaga sputigena, y C. albicans a excepción de Lactobacillus casei que presenta resistencia.
Se determinó que la concentración antimicrobiana frente a Capnocytophaga sputigena fue de $120 \mathrm{mg} / \mathrm{mL}$, teniendo como referencia al estándar de ciprofloxacino a una concentración de $4 \mathrm{mg} / \mathrm{ml}$.

Se determinó que la concentración antimicrobiana frente a Candida albicans fue de $90 \mathrm{mg} / \mathrm{ml} \mathrm{y} 120 \mathrm{mg} / \mathrm{mL}$, presentando una mejor actividad antimicrobiana a la concentración de $120 \mathrm{mgr} /$ $\mathrm{ml}$ teniendo como referencia al estándar de fluconazol a una concentración de $2 \mathrm{mg} / \mathrm{ml}$.

Se determinó que la concentración antimicrobiana frente al Streptococcus mutans fue de $90 \mathrm{mg} / \mathrm{ml}$ y $120 \mathrm{mg} / \mathrm{ml}$ presentando una mejor actividad a la concentración de $120 \mathrm{mgr} / \mathrm{ml}$ teniendo como referencia al estándar de ciprofloxacino a una concentración de $4 \mathrm{mg} / \mathrm{ml}$.

Se determinó que el Lactobacillus ca$s e i$, presenta resistencia antimicrobiana frente al extracto de Allium sativum, teniendo como referencia al estándar de ciprofloxacino a una concentración de $4 \mathrm{mg} / \mathrm{ml}$.

\section{Referencias bibliográficas}

1. Harris J, Cottrell L, Plummer S, Lloyd D. Antimicrobial properties of Allium sativum. Appl Microbiol Biotechnol 2001; 57(3):282-6.

2. García G. Respuesta tisular a una pasta tópica a base de Plantago mayor L. y Virus paradisi en gingivitis inducida en lagomorfos [Tesis de licenciatura en Odontología]. Lima: Universidad de San Martin de Porres; 2003.

3. Villalobos O, Salazar C, Ramírez G. Efecto de un enjuague bucal compuesto de Aloe vera en la placa bacteriana y la inflamación gingival. Acta Odontológica Venezolana 2001;39:(3) 26-27.

4. Días K. Determinación de la actividad antibacteriana in vitro de Minthostachys Griseb (Muña) frente a bacterias orales de importancia estomatología [Tesis de Bachiller]. Lima: Universidad Nacional Mayor de San Marcos; 2005.

5. Mercado S. Efecto antibacteriano in Vitro del ajo (Allium sativum) en la microflora bacteriana salival [Tesis de Bachiller]. Facultad de Odontología. Universidad Santa María de Arequipa. Perú. 2008.
6. Villanueva G. Acción antibacteriana del extracto de Allium sativum sobre Streptococcus mutans in vitro [Tesis para optar el título profesional de cirujano dentista]. Lima: Universidad San Martin de Porres; 2007.

7. Rojas R., et al. Antimicrobial activity of selected Peruvian medicinal plants. Journal of Ethnopharmacology. 2003;88(2-3):199-204.

8. Liébana J. Microbiologia oral. 2a Ed. Espańa. Edit. McGraw-Hill; 1995.677 p.

9. Ledezma E, et al. Sinergismo entre ajoeno y ketoconazol en aislamiento de Microsporum canis. Un estudio preliminar mediante la determinación de la concentración inhibitoria fraccional (CIF). Revista Iberoamericana Micológica 2008; 25(3):157-162.

10. García R. Evaluación de la inhibición del crecimiento de cinco cepas bacterianas patógenas por extractos acuosos de Allium sativum, Allium fistulosum y Allium cepa: Estudio preliminar in vitro. Bistua: Revista de la Facultad de Ciencias Básicas, 2005;5(2):68-79.

\section{Agradecimiento}

Agradecemos al Facultad de Odontología de la UNMSM por el apoyo económico para la ejecución de este estudio 